O OPEN ACCESS

phytobiomesjournal.org

\title{
Microbiomes in Ground Water and Alternative Irrigation Water, and Spinach Microbiomes Impacted by Irrigation with Different Types of Water
}

\author{
Ganyu Gu, ${ }^{1,2, \dagger}$ Hsin-Bai Yin, ${ }^{1,3}$ Andrea Ottesen, ${ }^{4}$ Samantha Bolten, ${ }^{1}$ Jitendra Patel, ${ }^{1}$ Steve Rideout, ${ }^{2}$ \\ and Xiangwu Nou ${ }^{1, \dagger}$ \\ ${ }^{1}$ Environmental Microbiology and Food Safety Laboratory, USDA-ARS, Beltsville, MD \\ ${ }^{2}$ Eastern Shore Agricultural Research and Extension Center, Virginia Tech, Painter, VA \\ ${ }^{3}$ University of Maryland, Baltimore County, Baltimore, MD \\ ${ }^{4}$ Center for Food Safety and Applied Nutrition, U.S. Food and Drug Administration, College Park, MD \\ Accepted for publication 13 April 2019.
}

\section{ABSTRACT}

Irrigation water, particularly if applied overhead, could be an important source of bacterial contamination to fresh produce. The colonization, survival, and proliferation of exogenous bacterial pathogens can be strongly influenced by the produce microbiota. In this study, spinach grown in an organic field was irrigated with ground water and potential alternative irrigation water including reclaimed wastewater, and urban runoff water, over a period of 2 weeks. Water and spinach samples were collected before and after irrigation for bacterial plate count, qPCR, and community profiling using $16 \mathrm{~S}$ rDNA high-throughput sequencing analyses. The average bacterial population densities on spinach $(6.50 \pm 0.04$ $\log$ CFU/g, $7.40 \pm 0.10 \log 16 \mathrm{~S}$ copies $/ g$ ) were significantly higher than those in irrigation water $(3.61 \pm 0.12 \log \mathrm{CFU} / \mathrm{ml}, 4.94 \pm 0.13$ $\log 16 \mathrm{~S}$ copies $/ \mathrm{ml})$. The composition and relative abundance of spinach microbiomes varied with different types of irrigation waters; however, the most abundant microbial taxa on spinach were not significantly affected by the irrigation with different types of water. Shigella, Salmonella, Listeria, Campylobacter spp., and pathogenic Escherichia coli were not detected in this study. This study provides information on the microbial ecology of diverse bacterial communities on spinach surface after irrigation by different types of water, which can benefit future studies on the interaction of microbes on produce, and the prevention of foodborne pathogens and plant disease.

Keywords: bacteriology, ecology, ground water, irrigation, microbial community, microbiome, roof-harvest water, spinach, waste water
${ }^{\dagger}$ Corresponding authors: G. Gu; ganyu.gu@ars.usda.gov,

and X. Nou; xiangwu.nou@ars.usda.gov

Mention of trade names or commercial products in this publication is solely for the purpose of providing specific information and does not imply recommendation or endorsement by the U.S. Department of Agriculture.

Funding: This project was partially funded by the USDA-ARS and Wilson College Specific Cooperative Agreement 58-1245-4-068.

*The $\boldsymbol{e}$-Xtra logo stands for "electronic extra" and indicates that four supplementary figures, one supplementary table, and two supplementary datasets are published online.

The author(s) declare no conflict of interest.

This article is in the public domain and not copyrightable. It may be freely reprinted with customary crediting of the source. The American Phytopathological Society, 2019
The phyllosphere of produce harbors many large and diverse microbial communities, where bacteria are typically the most abundant inhabitants (Lindow and Brandl 2003; Yang et al. 2001). Although most residential bacteria are commensal or symbiotic (Lindow and Brandl 2003; Vorholt 2012), plant pathogens and sometimes foodborne human pathogens can be members of these microbial communities (Brandl 2006; Hirano and Upper 2000). Recent and past outbreaks of foodborne diseases associated with fresh produce have raised concerns about foodborne pathogen contamination during fresh produce production and distribution (Berger et al. 2010; Gelting et al. 2011; Lynch et al. 2009). Fresh produce microbiota can have a profound effect on the survival and persistence of contaminating foodborne pathogens (Carter et al. 2012; Gu et al. 2013a; Lopez-Velasco et al. 2012).

Irrigation water is one of the major concerns as source of foodborne pathogens at the farm level. It can be contaminated by sewage overflows, polluted storm water runoff, and agricultural 
runoff (Gu et al. 2013c; Hintz et al. 2010; Solomon et al. 2002a; Uyttendaele et al. 2015). Many bacterial pathogens are capable of survival or even proliferation for extended time in contaminated irrigation water (Cevallos-Cevallos et al. 2014; Falardeau et al. 2017), depending on its aeration conditions (Semenov et al. 2011). Foodborne pathogens may be splash-dispersed by contaminated irrigation water and adhere to plant surface (Cevallos-Cevallos et al. 2012). They can enter through stomata and hydathodes (Gu et al. 2013b), and then persist or proliferate during production and ensuing storage/ distribution (Critzer and Doyle 2010; Franz and van Bruggen 2008).

Due to worsening fresh water scarcity and increasing global food demands, alternative water sources need to be explored for agricultural use. In recent years reclaimed wastewater (Wa) and urban runoff water (Rf) have been evaluated for this purpose (NortonBrandao et al. 2013; Salem et al. 2017; Yin et al. 2018a; Yin and Patel 2018). Wa, or recycled water, is the treated wastewater after removing solids and impurities, which can be reused for irrigation, groundwater recharge, and other purposes (Parsons et al. 2010; Scott et al. 2004). The urban Rf is usually collected from various surface runoff including the rooftops of buildings, which has been used as potable, and nonpotable, water sources in many countries with water shortage (Despins et al. 2009; Evans et al. 2006; Uba and Aghogho 2000). However, there are still concerns about the potential health risks and environmental impacts resulting from the application of unconventional water sources in agriculture, including the potential contamination of foodborne pathogens (Allende and Monaghan 2015; Norton-Brandao et al. 2013; Wang et al. 2017).

Understanding the impact of irrigation using alternative water sources on the composition and population of microbiota on the produce phyllosphere can provide knowledge to assess and prevent the potential risks for plant pathogen infection and contamination of foodborne pathogens during irrigation. Recent progress in high throughput DNA sequencing and sequence analyses (Bokulich et al. 2016; Goodwin et al. 2016) greatly facilitates identification and analysis of complex bacterial communities. The objectives of this study were to (i) compare the population and composition of bacterial communities in three different types of irrigation water, including ground water (Gr; control), Wa, and urban storm Rf; and (ii) investigate the shift in bacterial communities on the surface of field-grown spinach before and after irrigation.

\section{MATERIALS AND METHODS}

Spinach growth and irrigation water. Organic spinach (Gazelle F1 cultivar) was grown on experimental plots at an organic farm (Fulton Farm, Chambersburg, PA) in early October 2017. The soil type of the organic farm is Allegheny loam (fine-loamy, mixed, semi-active, mesic Typic Hapludults). Spinach seeds of cultivar Gazelle F1 were planted in six parallel plots $(5 \mathrm{~m} \times 2 \mathrm{~m})$ at a density of 330 seeds $/ \mathrm{m}^{2}$. Spinach seedlings were thinned when about $12 \mathrm{~cm}$ tall. Unless specified, the postemergence plant care was done following the standard organic agricultural practices of the farm, and Gr from a farm-owned well was used for overhead irrigation (Wyenandt et al. 2018).

Overhead irrigation by watering can with Wa or urban storm Rf started 6 weeks postseeding, with Gr as control. Wa was obtained from Chambersburg Wastewater treatment facility after secondary treatment, and urban Rf was harvested from the roofs of the academic buildings at Wilson College (Chambersburg, PA) during the weeks prior to the experiment. Both Wa and Rf water were collected about 2 weeks before the first irrigation and stored at $15^{\circ} \mathrm{C}$. Local weather information during the experiment was retrieved from the weather station located on the farm.
Water and spinach sampling. The spinach plots were randomized so that two plots each would receive weekly irrigation treatment with either Gr, Wa, or Rf water for 2 weeks. On day 0 and day 7, each plot was irrigated by overhead spray with 16 liters of designated irrigation water, and water samples (1 liter) used for irrigation were collected for microbiological and chemical analyses. For each plot, $35 \mathrm{~g}$ of spinach was randomly harvested on day 0 before irrigation (B), and on days 1, 4, 8, and 11 after first irrigation. Spinach and water samples were stored on ice and delivered to laboratory for processing within $5 \mathrm{~h}$.

Sample processing. Both water and spinach samples were split and tested in triplicates. To harvest bacteria on spinach phyllosphere, a 10-g portion of each spinach sample was immersed in $50 \mathrm{ml}$ of phosphate-buffered saline (PBS, pH 7.2, Thermo Fisher Scientific) in Whirl-Pak filter bags (Nasco, Fort Atkinson, WI) and sonicated at $40 \mathrm{kHz}$ for $2 \times 1 \mathrm{~min}$ with $30 \mathrm{~s}$ pulses in an ultrasonic waterbath (Branson, Richmond, VA), followed by gentle hand massaging. An aliquot was taken for bacterial plate counts, and the remaining filtrate was concentrated for DNA purification. Water $\mathrm{pH}$ and electrical conductivity (NTU, nephelometric turbidity units) measurements of irrigation water were determined using established procedures (Weng et al. 2016).

Bacterial enumeration. For enumeration by plate counting, water samples were decimally diluted and spiral plated on tryptic soy agar plates (TSA, Sigma, St. Louis, MO) in duplicates as described in a previous study (Gu et al. 2018). The filtrate of each spinach sample or its decimal serial dilutions were plated on TSA plates in duplicates. Plates were incubated at $30^{\circ} \mathrm{C}$ for 2 days and all colonies enumerated using a Flash \& Go automatic colony counter (IUL, Barcelona, Spain). Total bacterial population was also estimated by qPCR, as described in the section below.

PMA treatment and DNA extraction. For spinach samples, the filtrate $(45 \mathrm{ml})$ was centrifuged for $2 \mathrm{~min}$ at $1,000 \times g$ to remove coarse debris, and then $15 \mathrm{~min}$ at $4,500 \times g$ to precipitate bacterial cells. The precipitated cells were further concentrated by microcentrifugation $(14,000 \times g$ for $10 \mathrm{~min})$. Finally, pelleted cells were resuspended in $500 \mu \mathrm{l}$ of PBS with $50 \mu \mathrm{M}$ DNA-modifying dye propidium monoazide (PMA, Biotium, Fremont, CA). The cell suspension was incubated in dark for $10 \mathrm{~min}$ at room temperature, followed by light exposure for $15 \mathrm{~min}$ using the PMA-Lite LED Photolysis Device (Biotium, Fremont, CA). Cells were washed with PBS twice and collected by centrifugation at $14,000 \times g$ for $10 \mathrm{~min}$. Bacterial cells in irrigation water samples were collected by filtering $100 \mathrm{ml}$ of each water sample using a $0.22 \mu \mathrm{m}$ Millipore membrane (MilliporeSigma, Burlington, MA) in triplicate. Each membrane was soaked in $500 \mu \mathrm{l}$ of PBS with $50 \mu \mathrm{M}$ PMA and processed as above.

PMA-treated cells were resuspended in $150 \mu \mathrm{l}$ of TE buffer (Thermo Fisher Scientific) with lysozyme at $10 \mathrm{mg} / \mathrm{ml}$ (Epicentre, Madison, WI) and proteinase $\mathrm{K}$ at $5 \mathrm{mg} / \mathrm{ml}$ (Epicentre), and incubated at $37^{\circ} \mathrm{C}$ for $10 \mathrm{~min}$. Bacterial DNA from the PMA-treated samples was extracted using Mobio Powersoil DNA isolation kit (Qiagen, Gaithersburg, MD) following the supplier's instructions and stored at $-80^{\circ} \mathrm{C}$.

Quantitative real-time PCR (qPCR). qPCR targeting a highly conserved $180 \mathrm{bp}$ portion of 16S rDNA gene (Clifford et al. 2012) was performed on a Mx3005P QPCR system (Agilent technology Inc., Savage, MD) to estimate the total $16 \mathrm{~S}$ rDNA copy numbers as described previously (Gu et al. 2018). All PCR were performed in triplicate. The inferred absolute abundances of identified taxa in the surface DNA samples were calculated by multiplying the total $16 \mathrm{~S}$ rDNA copy numbers of each sample by the taxonomic relative abundance (RA) of each taxon in the sample calculated from the $16 \mathrm{~S}$ amplicon sequencing described below (Liang et al. 2015). 
16S rDNA high-throughput sequencing and sequence analysis. Sample DNAs were processed for 16S high-throughput sequencing following the Earth Microbiome Project protocol (Caporaso et al. 2011, 2012) using MiSeq (Illumina, San Diego, CA) with MiSeq Reagent 600-cycles v3 kit as reported previously (Gu et al. 2018). The barcoded primers, 515F and 806R, were used to amplify the $\sim 400$-bp 16S rDNA fragment (Apprill et al. 2015; Parada et al. 2016). PCR products were purified using AMPure XT Beads (Beckman Coulter Inc., Brea, CA). DNA concentration of each sample was determined using Qubit High-Sensitivity Assay kit (Life Technologies, Grand Island, NY). DNA samples were diluted to $4 \mathrm{nM}$ with EB buffer (Qiagen, Hilden, Germany) and pooled using $5 \mu \mathrm{l}$ of each sample. Five microliters $(5 \mu \mathrm{l})$ of the pooled DNA library was denatured by mixing with $5 \mu$ l of $0.2 \mathrm{~N} \mathrm{NaOH}$ and incubated at room temperature for $5 \mathrm{~min}$. Then $990 \mu \mathrm{l}$ of HT1 buffer (Illumina) was added to the DNA library to create a concentration of $20 \mathrm{pM}$. PhiX and the DNA library were then diluted to $12 \mathrm{pM}$ and pooled together at a 1:5 ratio. Six hundred microliters $(600 \mu \mathrm{l})$ of the final DNA library was loaded for MiSeq sequencing (Illumina).

Illumina sequence data were sorted based on unique barcodes and quality-controlled using the Quantitative Insights Into Microbial Ecology (Qiime2, version 2017.11, https://docs.qiime2.org/2017.11/) with plugins demux (https://github.com/qiime2/q2-demux), dada2 (Callahan et al. 2016) and feature-table (McDonald et al. 2012). Alpha and beta diversity analyses were performed using plugins alignment (Katoh and Standley 2013), phylogeny (Price et al. 2010), diversity (https://github.com/qiime2/q2-diversity), and emperor (Vazquez-Baeza et al. 2013). A pretrained Naive Bayes classifier based on the Greengenes 13_8 99\% operational taxonomic units (OTUs) database (http://greengenes.secondgenome.com/), which has been trimmed to include the 44 region of $16 \mathrm{~S}$ rDNA, bound by the $515 \mathrm{~F} / 806 \mathrm{R}$ primer pair, was applied to paired-end sequence reads to generate taxonomy tables. Taxonomic and compositional analyses were conducted by using plugins feature-classifier (https://github. com/qiime2/q2-feature-classifier), taxa (https:/github.com/qiime2/ q2-taxa), and composition (Mandal et al. 2015).

Statistical analysis. At each sampling time, three (technical) and six (two plots $\times$ three technical replicates) replicates were tested for each type of irrigation water and spinach sample, respectively. Bacterial populations (CFU values) and qPCR estimates (16S rDNA copy numbers) were log transformed to present the population densities for normalization. Analysis of variance (ANOVA) was performed to analyze the difference of both bacterial populations by plate count and $16 \mathrm{~S}$ rDNA copy numbers by qPCR among different types of samples. Pearson's correlation coefficients were calculated to evaluate the correlation between bacterial populations and 16S rDNA copy numbers among water and spinach samples. The shift in identified bacterial species on spinach after irrigation by different types of water was also analyzed by ANOVA. The differences of alpha diversity indexes, including evenness and Shannon index, and beta diversity analysis by the Weighted UniFrac method, among water and spinach samples were analyzed by the Kruskal-Wallis $\mathrm{H}$ test and permutational multivariate analysis of variance (PERMANOVA) analysis, respectively, in Qiime 2. All other statistical analyses were performed using SAS (SAS release 9.3, SAS Institute Inc., Cary, NC). Except when stated otherwise, $P$ values of $<0.05$ were considered statistically significant.
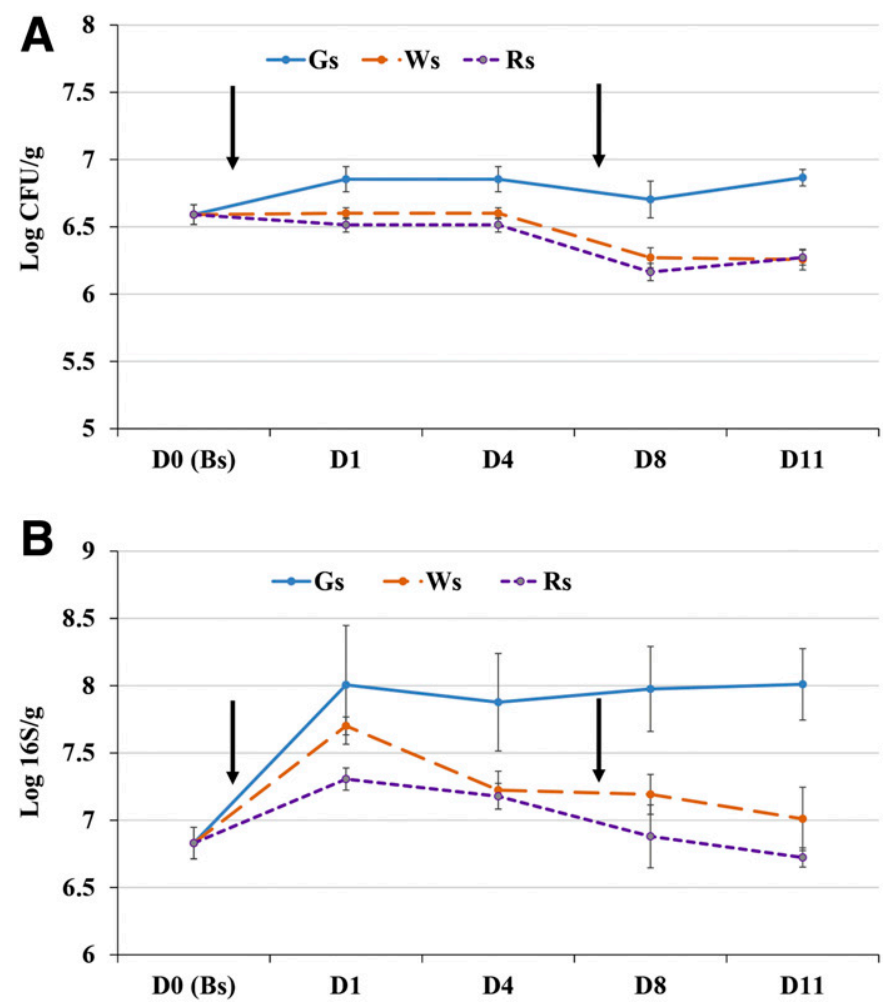

Fig. 1. A, Total mesophilic aerobic plate count and B, 16S rDNA quantification of live bacteria on spinach samples before and after irrigation. Gs, spinach samples after irrigation by ground water Gr; Ws, spinach samples after irrigation by reclaimed wastewater Wa; $R s$, spinach samples after irrigation by roof-harvested water Rf; Bs, spinach samples before irrigation; and D0 to D11 denote the sampling dates of the experiment. Twelve replicates were tested for each treatment per sampling time. Arrows point out the two irrigation times on day 0 (Monday of week 1) and day 7 (Monday of week 2). Bars indicate standard errors.

TABLE 1

Chemical and microbiological comparison of irrigation water ${ }^{2}$

\begin{tabular}{lccccc}
\hline Water & Time (day) & Conductivity $(\mathrm{dS} / \mathrm{m})$ & $\mathrm{pH}$ & APC (log CFU/ml) & 16S rDNA (log copy/ml) \\
\hline $\mathrm{Gr}$ & 0 & 428 & 7.6 & $2.76 \pm 0.06 \mathrm{c}$ & $3.92 \pm 0.04 \mathrm{~b}$ \\
\hline $\mathrm{Wa}$ & 7 & 445 & 7.61 & $3.75 \pm 0.05 \mathrm{a}$ & $4.58 \pm 0.07 \mathrm{ab}$ \\
\hline & 0 & 481 & 7.84 & $3.77 \pm 0.04 \mathrm{a}$ & $4.98 \pm 0.02 \mathrm{a}$ \\
\hline $\mathrm{Rf}$ & 7 & 510 & 7.85 & $4.22 \pm 0.01 \mathrm{a}$ & $5.34 \pm 0.04 \mathrm{a}$ \\
\hline & 0 & 30 & 8.02 & $3.24 \pm 0.05 \mathrm{~b}$ & $5.31 \pm 0.01 \mathrm{a}$ \\
\hline
\end{tabular}

${ }^{z} \mathrm{Gr}$, ground water; Wa, reclaimed water; and Rf, roof-harvested rainwater. Time indicates irrigation date of the experiment. Letters denote the significance levels of bacterial populations among irrigation water samples $(P<0.05)$. 


\section{RESULTS AND DISCUSSION}

Irrigation water characterization. Key physiochemical and microbiological characteristics, including acidity, ionic strength, and microbial load were compared for the water used for irrigation
(Table 1). Both Gr and Wa exhibited higher electrical conductivity than Rf, indicating higher salt content. This was expected since Rf was mostly rainwater. All three types of irrigation water exhibited slightly to moderately alkaline $\mathrm{pH}$. The higher $\mathrm{pH}$ in $\mathrm{Rf}$ water could be caused by leaching of roofing chemicals to the rain water, which
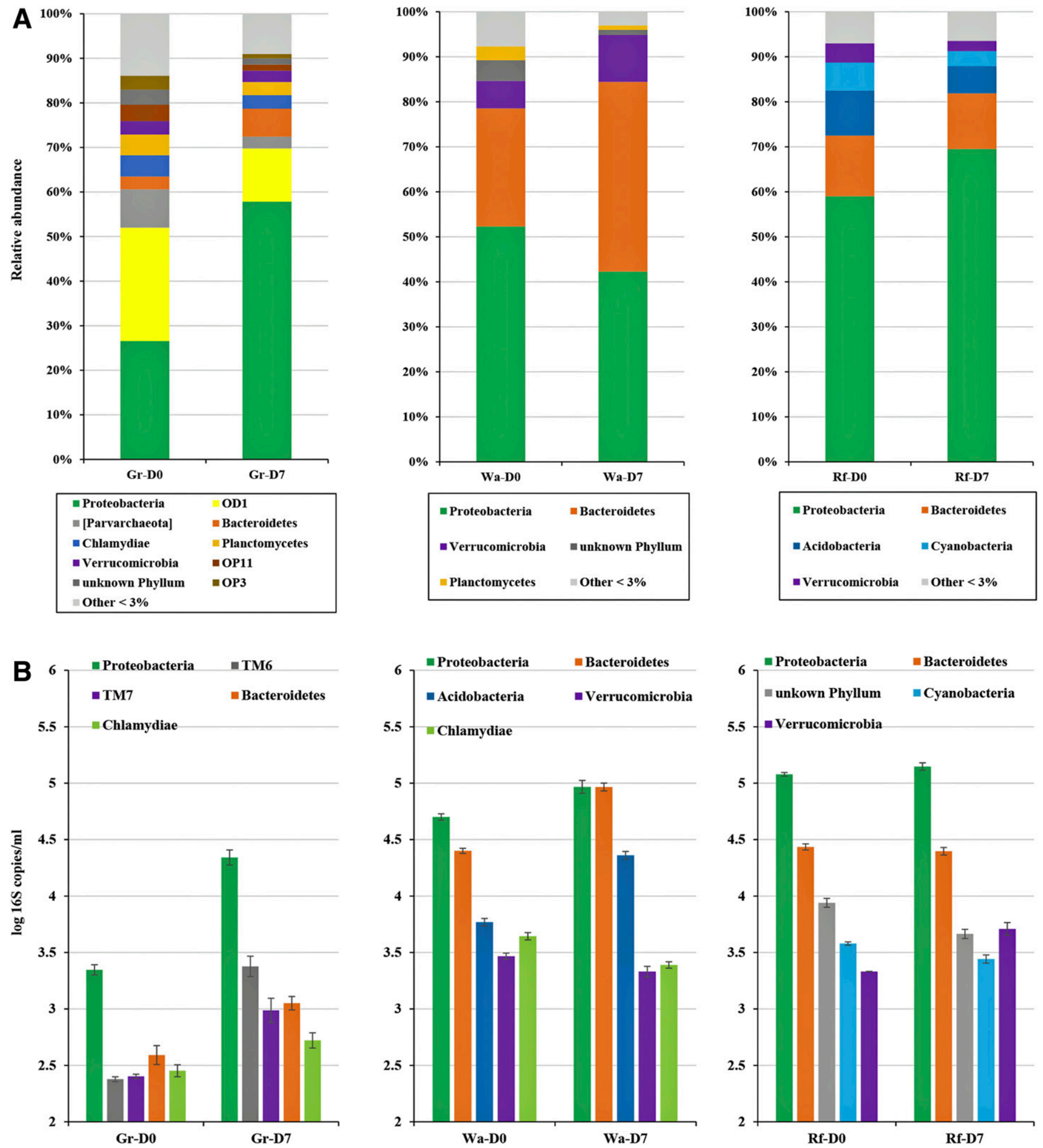

Fig. 2. A, Relative abundance of the dominant bacterial phyla (relative abundance $>3 \%$ ) and $\mathbf{B}$, population of the top five phyla in the three types of irrigation water applied on day 0 (D0) and day 7 (D7). Gr, ground water; Wa, reclaimed wastewater; and Rf, roof-harvested water. A, Only phyla comprising $>3 \%$ (average relative abundance) of the bacteria identified in at least one type of water sample were included. B, Bars represent standard errors. Three technical replicates were tested for each of the three types of irrigation water samples at each sampling time. 
had minimal buffering capacity due to low ionic strength. The average bacterial populations in $\mathrm{Gr}$, Wa, and $\mathrm{Rf}$ irrigation water samples were $3.25 \pm 0.56$ (mean \pm standard deviation), $4.00 \pm 0.25$, and $3.59 \pm 0.39 \log \mathrm{CFU} / \mathrm{ml}$, respectively (Table 1). Bacterial population in Wa in week 1 was higher than that in $\mathrm{Gr}$ and $\mathrm{Rf}$ water $(P<0.05)$, while the difference was not significant in week 2 . The estimated bacterial $16 \mathrm{~S}$ rDNA copy numbers in water samples by qPCR were significantly correlated with the populations measured by plate count. Bacterial $16 \mathrm{~S}$ rDNA levels in the three types of irrigation water were similar, except lower levels in Gr samples during the first week (Table 1).

Microbial load on spinach surface before and after irrigation. Total bacterial populations on spinach were determined by nonselective plating and by qPCR (Fig. 1). The culturable bacterial populations on spinach were $6.6 \log \mathrm{CFU} / \mathrm{g}$ before the irrigation events, as determined by growth on TSA plates. This population slightly increased (by $0.3 \mathrm{log}$ ) 1 day after irrigation with $\mathrm{Gr}$ water. Such increase was not observed after irrigation with either Wa or Rf. On day 8, a day after the second irrigation event, the bacterial populations on all irrigated spinach showed a moderate decrease, which seemed to recover to a different extent after an additional 3 days of growth. This decrease also coincided with local precipitation after the previous sampling (Supplementary Fig. S1).

The estimated bacterial $16 \mathrm{~S}$ rDNA copy numbers in spinach samples by qPCR were significantly correlated with the populations measured by plate count. The approximately 1 log higher counts in $16 \mathrm{~S}$ rDNA copy numbers than the respective plate counts were
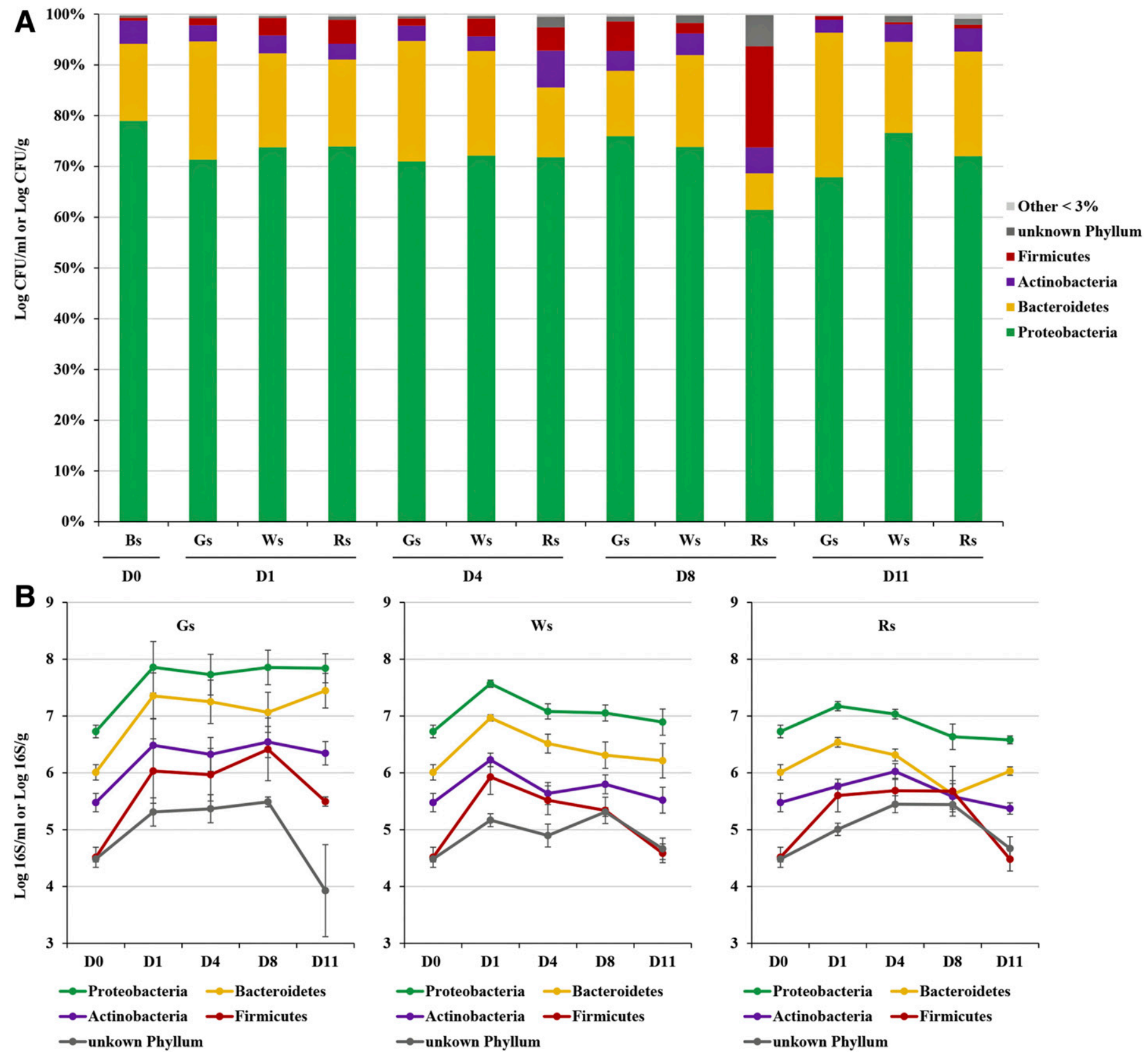

Fig. 3. A, Relative abundance of the dominant bacterial phyla (relative abundance $>3 \%$ ) and $\mathbf{B}$, population of the top five phyla on spinach before and after irrigation. A, Only phyla comprising $>3 \%$ (average relative abundance) of the bacteria identified in at least one type of sample were included. B, Bars represent standard errors. Six replicates (two plots $\times$ three technical replicates) were tested for each type of spinach sample at each sampling time. 
consistent with the multicopies of $16 \mathrm{~S}$ rDNA in bacterial cells, and with the expected presence of viable but nonculturable (VBNC) bacterial cells, which were detected by qPCR but not by the culturedependent method using carbon-rich media (Ramamurthy et al. 2014; Vetrovsky and Baldrian 2013). Bacterial populations on spinach measured by either plate count or by qPCR estimation did not significantly change after 2-week irrigations by any of the three types of water. This was consistent with the significantly lower bacterial counts in the irrigation water in comparison with that on the spinach plants.
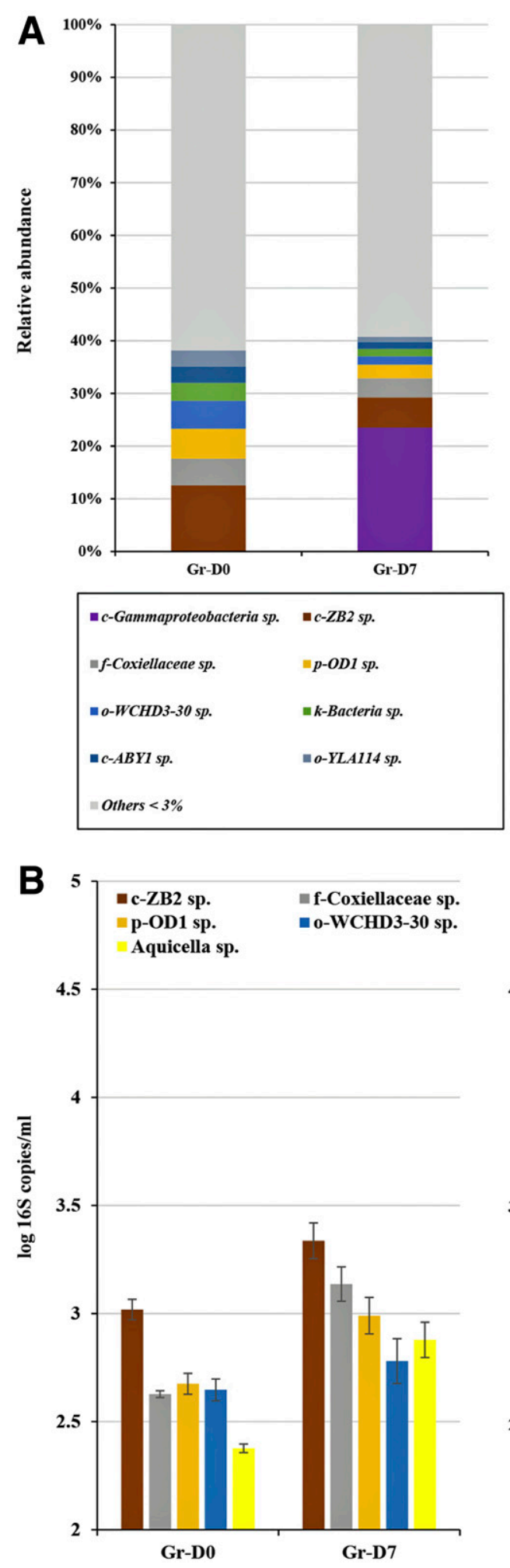
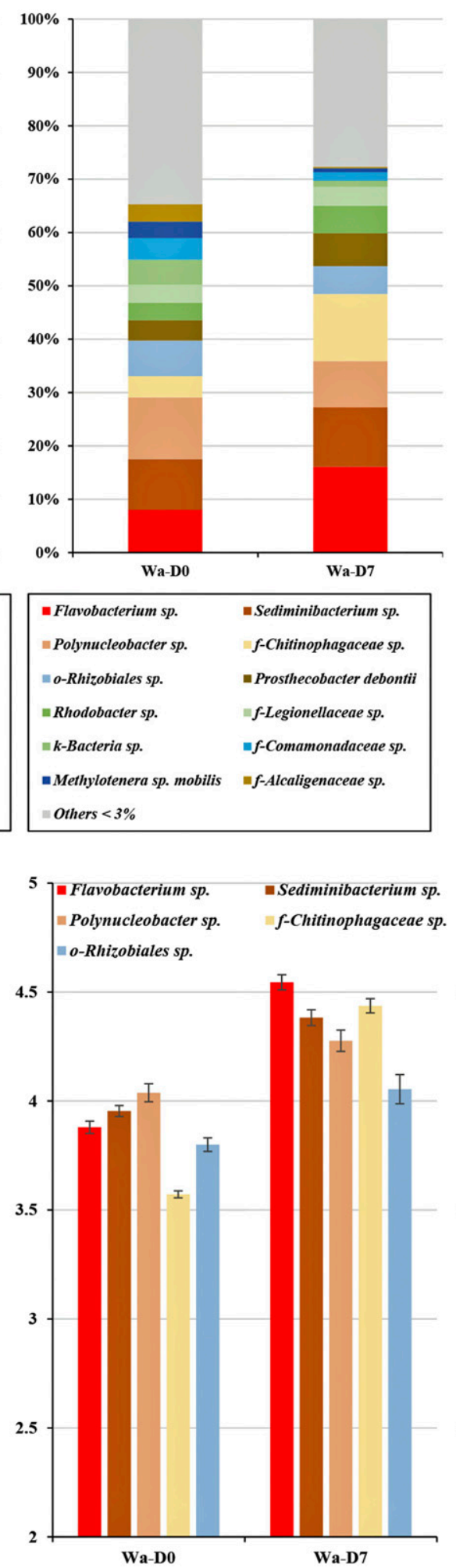
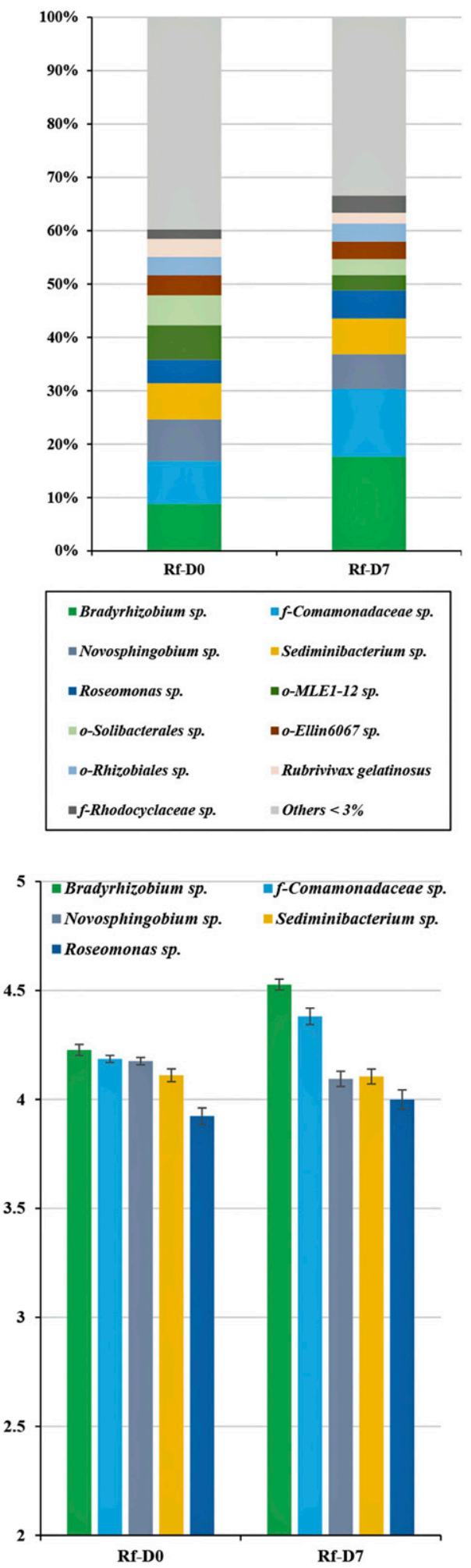

Fig. 4. A, Relative abundance of major bacteria species (relative abundance $>3 \%$ ) and B, population of the top five species in the three types of irrigation water applied on day 0 and day 7 . A, Only species comprising $>3 \%$ (average relative abundance) of the bacteria identified in at least one type of sample were included. B, Bars represent standard errors. Three replicates were tested for each of the three types of irrigation water samples per sampling time. 
Microbiota diversity in irrigation water and on spinach as determined by 16S rDNA high-throughput sequencing. The v4 region of $16 \mathrm{~S}$ rDNA was targeted for sequencing analyses, and the sequencing data have been submitted to NCBI (accession number PRJNA428487). After paired-end merge and quality control analyses using Qiime2, 16S rDNA high-throughput sequencing of the 96 samples, including 18 irrigation water and 78 spinach samples, generated 9,021,027 sequence reads ( $253 \mathrm{bp}$ ) in total, with a range of 27,066 to 163,862 reads per sample. Queries to the Greengene database using these sequences identified a total of 10,016 OTUs in the 96 samples, including 577 Archaea, 9,211 bacteria, 171 eukaryote (chloroplast and mitochondria), and 57 unassigned OTUs. All eukaryote reads, which counted for $4.49 \%$ of the total 9,021,027 reads, and unassigned reads $(0.02 \%)$ were purged prior to data analysis of bacterial communities on surfaces of spinach (Supplementary Dataset
S1). The 577 Archaea OTUs were further classified as 3 phyla and 23 species, while the bacteria OTUs were classified into 48 phyla and 834 species (Supplementary Dataset S2). Among the over 10,000 OTUs identified from water and spinach samples, at least 14,68 , and $88 \%$ were assigned to species, genus, and family levels, respectively. About $0.02 \%$ of the total paired-end reads remained unassigned, and $1.28 \%$ could only be classified to the Bacteria domain, which may denote novel sequences that have not been documented in the Greengenes database.

A subset $(27,022)$ of the paired-end reads of each water and spinach sample were randomly selected for alpha and beta diversity analyses, which showed stable values for rarefaction of observed OTUs and Faith-PD values in all tested samples (Supplementary Fig. S2). The observed OTUs and Faith-PD values were significantly higher in Gr water samples, while the difference among the
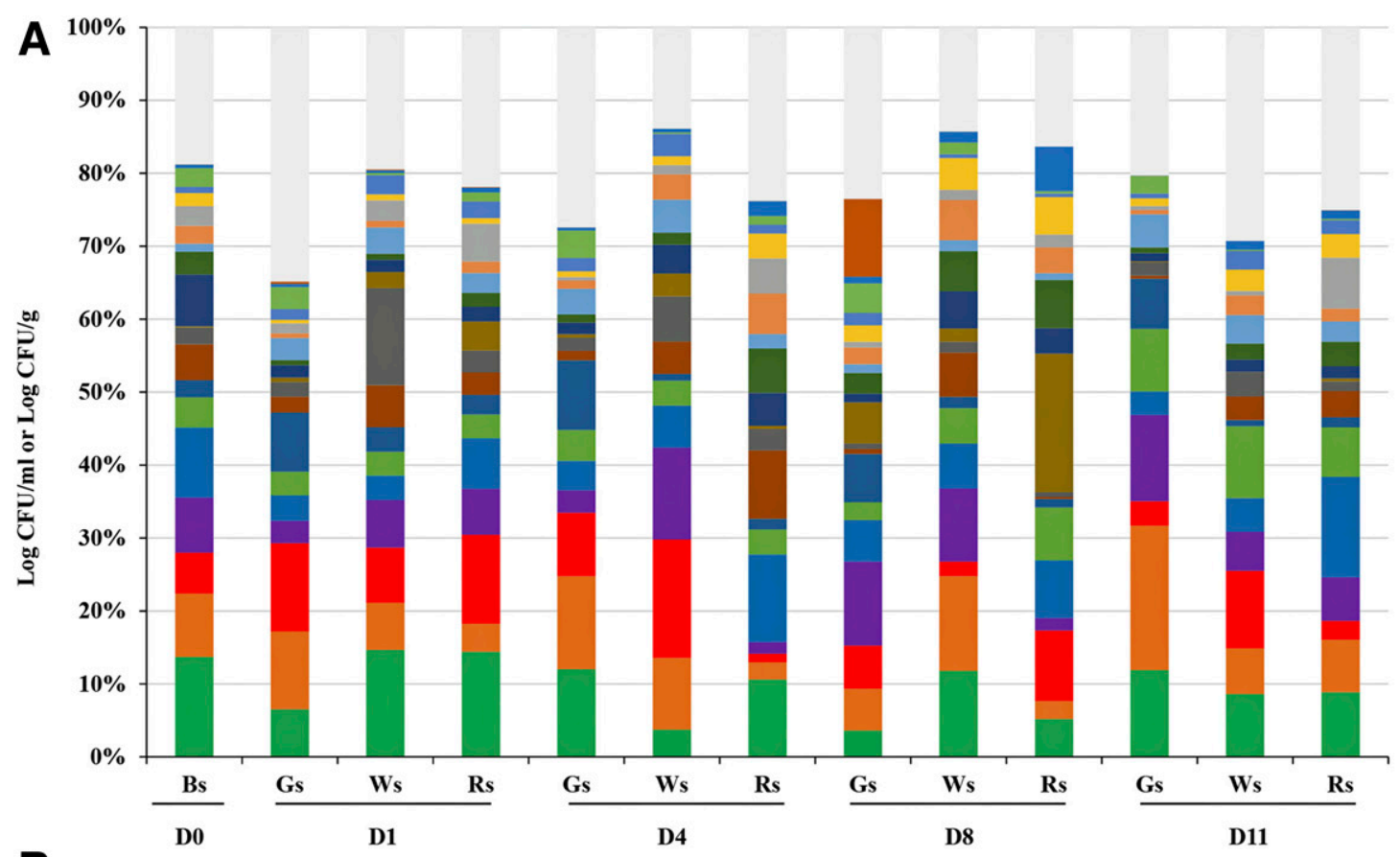

Erwinia sp.

- Pedobacter sp.

- $f$-Enterobacteriaceae sp.

- Luteibacter rhizovicinus

- Sphingomonas sp.

- Agrobacterium sp.

- Pseudomonas sp. 1

- Alkanindiges sp.

Erwinia sp. 2

- Enterococcus sp.

- Sphingomonas yabuuchiae

- Methylobacterium adhaesivum

n Chryseobacterium sp.

f-Methylobacteriaceae sp.

- Hymenobacter sp.

Methylobacterium sp.

- $f$-Sphingobacteriaceae sp.

- Pseudomonas sp. 2

n-Bacteria sp.

- $f$-Aeromonadaceae sp.

Others $<3 \%$
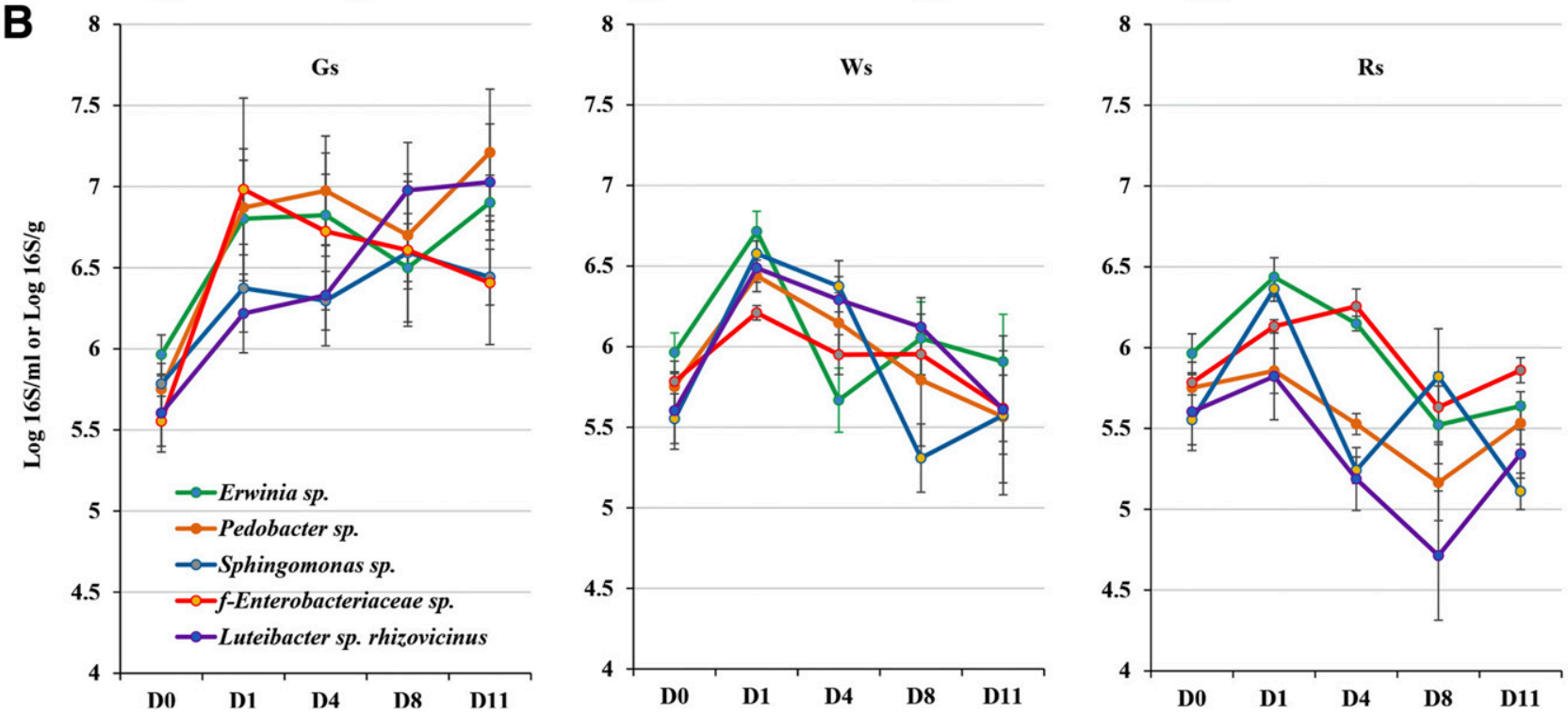

Fig. 5. A, Relative abundance of major bacteria species (relative abundance $>3 \%$ ) and B, population of the top five species on spinach before and after irrigation. A, Only species comprising $>3 \%$ (average relative abundance) of the bacteria identified in at least one type of sample were included. B, Bars represent standard errors. Six replicates were tested for each type of spinach sample per sampling time. 
other water and spinach samples were not significant (Supplementary Fig. S3). Based on the composition of bacterial communities, the three types of irrigation water samples were separated from spinach samples (Supplementary Fig. S4). The distance between Wa and Rf irrigated spinach were closer compared with spinach samples irrigated by Gr water. The unconspicuous changes of bacterial communities on spinach after irrigation might be associated with the significantly lower concentrations of bacteria in irrigation water as well as the high densities and diversity of established bacteria on the surface of organically grown spinach plants.

Composition of irrigation water and spinach microbiota. Proteobacteria was the top phylum with RA of 26.6 to $57.9 \%$ in Gr, 42.3 to $52.3 \%$ in $\mathrm{Wa}$, and 59.0 to $69.5 \%$ in Rf water samples (Fig. 2 ), which is in agreement with a previous study of bacterial community in surface and Gr (Telias et al. 2011). It was also the phylum with the highest abundance in the tested spinach samples, ranging from 61.5 to $79.0 \%$ (Fig. 3). The phyla with the second highest RA on spinach was Bacteroidetes (12.9 to 28.5\%), except for spinach samples collected a day after irrigation by Rf in week 2 (7.2\%). Actinobacteria and Firmicutes were the other two major phyla identified from spinach samples.

At the genus and species levels, the most abundant bacteria ( $>3 \%$ RA) were different among the three types of irrigation water (Fig. 4).
Most of these bacteria remained at similar RA levels in week 1 and week 2 water samples, except for Gr water, where a previously undetected bacterium of the Gamma-proteobacteria class became the most abundant species in week 2 . The high abundance of this previously undetected species in week 2 water samples suggested a potential event between the samplings that introduced exogenous bacteria into $\mathrm{Gr}$ water, such as the rain event transferring soil bacteria to the groundwater. None of the most abundant bacteria in $\mathrm{Gr}$ water could be identified to genus level, which might suggest the abundant presence in the Gr water samples of live bacteria that were less frequently isolated. No significant shift was observed for the population of the top five bacterial species in Wa and $\mathrm{Rf}$ over the period of 2 weeks (Fig. 4B).

Erwinia sp.1, Pedobacter sp., Sphingomonas sp., an unidentified species of the family Enterobacteriaceae, and Luteibacter rhizovicinus were the top five bacterial species on spinach both before and after irrigation regardless the source of irrigation water (Fig. 5). The 16S rDNA levels of the top five bacteria, except the unidentified Enterobacteriaceae species, were significantly increased after the 2-week irrigation by Gr water, whereas the populations did not significantly change after Wa or Rf irrigation. Most of the prevalent bacterial species identified on the spinach have previously been isolated from diverse land and water habitats, especially from

TABLE 2

List of bacteria existing in irrigation water that resulted in significantly increased populations on spinach one day after first or second irrigation ${ }^{w}$

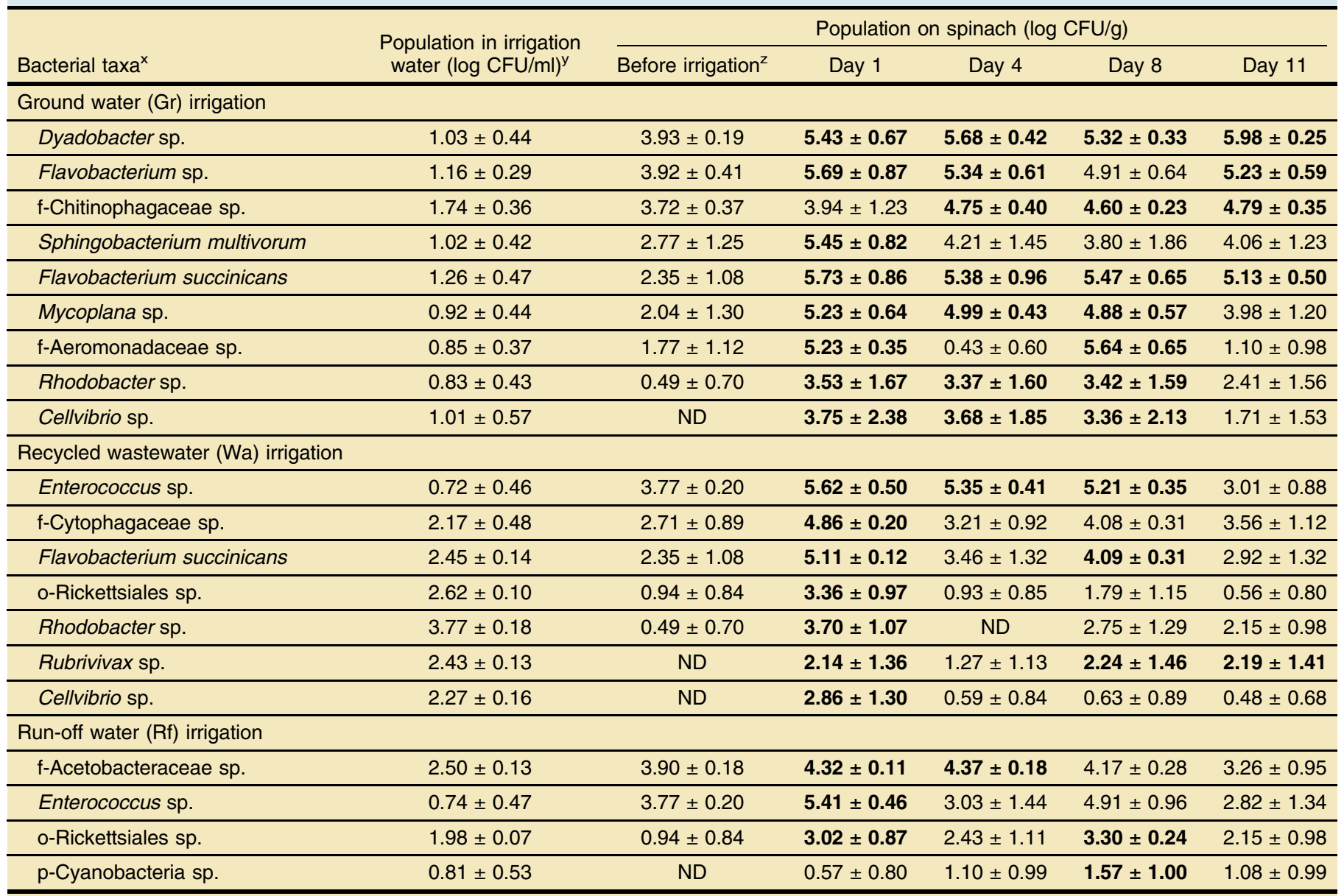

w Average population of bacteria on spinach before irrigation $<4 \log 16 \mathrm{~S}$ copies/g.

$x$ Letters 0 - and $\mathrm{f}$ - in front denote an undetermined species that has been assigned to the order and family levels, respectively.

y $16 \mathrm{~S}$ rDNA copies/ml for water samples $\mathrm{Gr}$, ground water; Wa, reclaimed water; and Rf, roof-collection water.

z $16 \mathrm{~S}$ rDNA copies/g for the rest of the spinach samples. Significantly increased bacterial populations on spinach after irrigation are labeled in bold $(P<0.05)$. Letters, p-, o-, and f-, in front denote undetermined species that have been assigned to the phylum, order, and family levels, respectively. 
plants (Gnanamanickam 2006). Multiple Erwinia spp. are plant pathogens, and certain species, such as E. carotovora, play majors roles in fresh produce soft rot and spoilage during postharvest storage and marketing (Tournas 2005). In contrast, other species, such as $L$. rhizovicinus, have been reported to promote plant growth (Guglielmetti et al. 2013). Two species of genus Pseudomonas were also among the most prevalent bacteria on the spinach samples, which has been previously reported as one of the dominant taxa on raw spinach (Gu et al. 2018; Lopez-Velasco et al. 2013).

The 16S rDNA for common foodborne pathogens such as Shigella, Salmonella, Listeria, and Campylobacter spp. was not detected from water and spinach samples in this study. E. coli rDNA was identified on spinach samples and in Gr water in both weeks. Culture based microbiological analyses confirmed the presence of generic but not enteropathogenic E. coli in these samples (Yin et al. 2018b). However, rDNA for several bacterial genera, which include pathogenic or opportunistic pathogenic species (Uyttendaele et al. 2015), were identified in this study. A Vibrio sp. was isolated from one spinach sample 4 days after irrigation in week 1 . One Legionella sp. was identified in most water samples (average $1.74 \pm$ $0.16 \log 16 \mathrm{~S}$ copies/ml), and on one Gr irrigated and two Rf irrigated spinach samples. Bacteroides fragilis and Veillonella sp. were also detected at lower levels on spinach as E. coli in week 2. An Enterococcus sp. was detected in all three types of irrigation water (average $0.72 \pm 0.21 \log 16 \mathrm{~S}$ copies $/ \mathrm{ml}$ ) and from all types of irrigated spinach samples (average $4.47 \pm 0.22 \log 16 \mathrm{~S}$ copies/g).

Shift in bacterial communities on spinach surface after irrigation by three different types of water source. Bacterial population dynamics is perturbed to various degrees by the irrigation events and other uncontrolled natural events. Multiple bacterial species on spinach increased significantly in relative abundance after irrigation in at least one of the 2 weeks, which could have resulted from activation of innate dormant cells, transfer of bacteria from irrigation water (Table 2), and the ensuing growth. The average $16 \mathrm{~S}$ rDNA levels of nine bacterial species, ranging from 0.83 to $1.74 \mathrm{log}$ copies $/ \mathrm{ml}$ in $\mathrm{Gr}$ water, significantly increased on spinach one day after irrigation. Similarly, seven and four bacterial species were identified to be potentially transmitted from Wa and Rf irrigation water onto spinach, respectively, during the study. Among these bacteria, the increase in Flavobacterium succinicans, Rhodobacter sp., and Cellvibrio sp., occurred after $\mathrm{Gr}$ and Wa irrigation, and increase in Enterococcus sp. and a species of family Rickettsiales after Wa and Rf irrigation. Gr irrigation resulted in significantly higher populations of Dyadobacter sp. and Flavobacterium succinicans on all tested spinach samples. These bacteria have been isolated from a diverse range of environments worldwide, including water, soil, and plant phyllosphere (Delmotte et al. 2009; Good et al. 2015; Jiao et al. 2015; Suarez et al. 2014).

Populations of other bacteria also increased on spinach after the 2 weeks of irrigation (Supplementary Table S1). However, the significantly higher levels on spinach compared with the same species in corresponding water samples indicated that the increase may be caused by other factors besides the direct transmission. For example, a Skermanella sp. was not detected in Rf water samples, but its population on spinach was significantly increased from less than 0.5 to over $3 \log 16 \mathrm{~S}$ copies/g after Rf irrigation.

Most of the dominant microbial taxa on spinach surface were not significantly affected by irrigation with different types of water. The top five bacterial species on spinach were detected from all three types of irrigation water samples (Fig. 5), but the populations were not significantly increased after irrigation, which might be associated with their colonization capabilities and the high initial levels on spinach before irrigation. In addition, none of the top five bacteria identified in sampled water resulted in significant increases on spinach after irrigation. These results support previous studies demonstrating that the populations of dominant bacterial groups on plant surfaces were not strongly affected by irrigation (Telias et al. 2011). Nevertheless, it can be expected that bacterial species including foodborne pathogens from contaminated irrigation water are capable of being transmitted to and colonizing irrigated produce in the field, without showing dominant presence (Solomon et al. 2002b; Williams et al. 2013). The transient or persistent presence of the pathogens will be dependent of the interactions with the environment and the indigenous microbiota (Franz et al. 2008; Semenov et al. 2010).

Conclusion. The microbiome in $\mathrm{Gr}$ on a produce farm and potential alternative irrigation water (Wa water and urban storm $\mathrm{Rf}$ ) and on correspondingly irrigated spinach phyllosphere was examined using 16S rDNA copy survey. Significant differences in microbiome composition were observed for the three types of irrigation water. Despite such differences, the impact of irrigation with alternative water on the spinach microbiota was limited. The most abundant bacterial species retained a dominant presence on spinach surface after irrigation. Commonly known foodborne pathogens, including Shigella, Salmonella, Listeria, Campylobacter spp., and pathogenic E. coli were not detected from either the irrigation water or the spinach samples. However, irrigation resulted in an increase of multiple bacterial species on spinach, including species of potential opportunistic pathogens. This study provides contextual information on the microbial ecology of diverse bacterial communities in different types of irrigation water and on organic spinach in the field, and scientific data to determine the impact of irrigation on plant phyllosphere microbiomes.

\section{ACKNOWLEDGMENTS}

We thank C. Myers at the Wilson College for spinach plot management, and P. Ramachandran and E. Reed at the U.S. Food and Drug Administration for laboratory assistance on $16 \mathrm{~S}$ rDNA sequencing.

\section{LITERATURE CITED}

Allende, A., and Monaghan, J. 2015. Irrigation water quality for leafy crops: A perspective of risks and potential solutions. Int. J. Environ. Res. Public Health $12: 7457-7477$

Apprill, A., McNally, S., Parsons, R., and Weber, L. 2015. Minor revision to V4 region SSU rRNA 806R gene primer greatly increases detection of SAR11 bacterioplankton. Aquat. Microb. Ecol. 75:129-137.

Berger, C. N., Sodha, S. V., Shaw, R. K., Griffin, P. M., Pink, D., Hand, P., and Frankel, G. 2010. Fresh fruit and vegetables as vehicles for the transmission of human pathogens. Environ. Microbiol. 12:2385-2397.

Bokulich, N. A., Lewis, Z. T., Boundy-Mills, K., and Mills, D. A. 2016. A new perspective on microbial landscapes within food production. Curr. Opin. Biotechnol. 37:182-189.

Brandl, M. T. 2006. Fitness of human enteric pathogens on plants and implications for food safety. Annu. Rev. Phytopathol. 44:367-392.

Callahan, B. J., McMurdie, P. J., Rosen, M. J., Han, A. W., Johnson, A. J., and Holmes, S. P. 2016. DADA2: High-resolution sample inference from Illumina amplicon data. Nat. Methods 13:581-583.

Caporaso, J. G., Lauber, C. L., Walters, W. A., Berg-Lyons, D., Huntley, J., Fierer, N., Owens, S. M., Betley, J., Fraser, L., Bauer, M., Gormley, N., Gilbert, J. A., Smith, G., and Knight, R. 2012. Ultra-high-throughput microbial community analysis on the Illumina HiSeq and MiSeq platforms. ISME J. 6:1621-1624.

Caporaso, J. G., Lauber, C. L., Walters, W. A., Berg-Lyons, D., Lozupone, C. A., Turnbaugh, P. J., Fierer, N., and Knight, R. 2011. Global patterns of $16 \mathrm{~S}$ rRNA diversity at a depth of millions of sequences per sample. Proc. Natl. Acad. Sci. USA 108(suppl. 1):4516-4522.

Carter, M. Q., Xue, K., Brandl, M. T., Liu, F. F., Wu, L. Y., Louie, J. W., Mandrell, R. E., and Zhou, J. Z. 2012. Functional metagenomics of 
Escherichia coli $\mathrm{O} 157: \mathrm{H} 7$ interactions with spinach indigenous microorganisms during biofilm formation. PLoS One 7:e44186.

Cevallos-Cevallos, J. M., Danyluk, M. D., Gu, G., Vallad, G. E., and van Bruggen, A. H. C. 2012. Dispersal of Salmonella by rain splash onto tomato plants. J. Food Prot. 75:472-479.

Cevallos-Cevallos, J. M., Gu, G. Y., Richardson, S. M., Hu, J. H., and van Bruggen, A. H. C. 2014. Survival of Salmonella enterica Typhimurium in water amended with manure. J. Food Prot. 77:2035-2042.

Clifford, R. J., Milillo, M., Prestwood, J., Quintero, R., Zurawski, D. V., Kwak, Y. I., Waterman, P. E., Lesho, E. P., and Mc Gann, P. 2012. Detection of bacterial 16S rRNA and identification of four clinically important bacteria by real-time PCR. PLoS One 7:e48558.

Critzer, F. J., and Doyle, M. P. 2010. Microbial ecology of foodborne pathogens associated with produce. Curr. Opin. Biotechnol. 21:125-130.

Delmotte, N., Knief, C., Chaffron, S., Innerebner, G., Roschitzki, B., Schlapbach, R., von Mering, C., and Vorholt, J. A. 2009. Community proteogenomics reveals insights into the physiology of phyllosphere bacteria. Proc. Natl. Acad. Sci. USA 106:16428-16433.

Despins, C., Farahbakhsh, K., and Leidl, C. 2009. Assessment of rainwater quality from rainwater harvesting systems in Ontario, Canada. J Water Supply Res Technol 58:117-134.

Evans, C. A., Coombes, P. J., and Dunstan, R. H. 2006. Wind, rain and bacteria: The effect of weather on the microbial composition of roof-harvested rainwater. Water Res. 40:37-44.

Falardeau, J., Johnson, R. P., Pagotto, F., and Wang, S. Y. 2017. Occurrence, characterization, and potential predictors of verotoxigenic Escherichia coli, Listeria monocytogenes, and Salmonella in surface water used for produce irrigation in the lower mainland of British Columbia, Canada. PLoS One 12: e0185437.

Franz, E., Semenov, A. V., and van Bruggen, A. H. C. 2008. Modelling the contamination of lettuce with Escherichia coli O157:H7 from manureamended soil and the effect of intervention strategies. J. Appl. Microbiol. 105: 1569-1584.

Franz, E., and van Bruggen, A. H. C. 2008. Ecology of E. coli O157:H7 and Salmonella enterica in the primary vegetable production chain. Crit. Rev. Microbiol. 34:143-161.

Gelting, R. J., Baloch, M. A., Zarate-Bermudez, M. A., and Selman, C. 2011. Irrigation water issues potentially related to the 2006 multistate $E$. coli O157:H7 outbreak associated with spinach. Agric. Water Manage. 98: 1395-1402.

Gnanamanickam, S. S. 2006. Plant-Associated Bacteria. Springer, Dordrecht.

Good, C., Davidson, J., Wiens, G. D., Welch, T. J., and Summerfelt, S. 2015. Flavobacterium branchiophilum and $F$. succinicans associated with bacterial gill disease in rainbow trout Oncorhynchus mykiss (Walbaum) in water recirculation aquaculture systems. J. Fish Dis. 38:409-413.

Goodwin, S., McPherson, J. D., and McCombie, W. R. 2016. Coming of age: Ten years of next-generation sequencing technologies. Nat. Rev. Genet. 17: 333-351.

Gu, G., Cevallos-Cevallos, J. M., Vallad, G. E., and van Bruggen, A. H. C. 2013a. Organically managed soils reduce internal colonization of tomato plants by Salmonella enterica serovar Typhimurium. Phytopathology 103: 381-388.

Gu, G., Cevallos-Cevallos, J. M., and van Bruggen, A. H. C. 2013b. Ingress of Salmonella enterica Typhimurium into tomato leaves through hydathodes. PLoS One 8:e53470.

Gu, G., Luo, Z., Cevallos-Cevallos, J. M., Adams, P., Vellidis, G., Wright, A., and van Bruggen, A. H. C. 2013c. Factors affecting the occurrence of Escherichia coli $\mathrm{O} 157$ contamination in irrigation ponds on produce farms in the Suwannee River Watershed. Can. J. Microbiol. 59:175-182.

Gu, G., Ottesen, A., Bolten, S., Ramachandran, P., Reed, E., Rideout, S., Luo, Y. G., Patel, J., Brown, E., and Nou, X. 2018. Shifts in spinach microbial communities after chlorine washing and storage at compliant and abusive temperatures. Food Microbiol. 73:73-84.

Guglielmetti, S., Basilico, R., Taverniti, V., Arioli, S., Piagnani, C., and Bernacchi, A. 2013. Luteibacter rhizovicinus MIMR1 promotes root development in barley (Hordeum vulgare L.) under laboratory conditions. World J Microb Biot 29:2025-2032.

Hintz, L. D., Boyer, R. R., Ponder, M. A., Williams, R. C., and Rideout, S. L. 2010. Recovery of Salmonella enterica Newport introduced through irrigation water from tomato (Lycopersicum esculentum) fruit, roots, stems, and leaves. HortScience 45:675-678.

Hirano, S. S., and Upper, C. D. 2000. Bacteria in the leaf ecosystem with emphasis on Pseudomonas syringae - a pathogen, ice nucleus, and epiphyte. Microbiol. Mol. Biol. Rev. 64:624-653.
Jiao, H. H., Luo, J. X., Zhang, Y. M., Xu, S. J., Bai, Z. H., and Huang, Z. B. 2015. Bioremediation of petroleum hydrocarbon contaminated soil by Rhodobacter sphaeroides biofertilizer and plants. Pak. J. Pharm. Sci. 28: 1881-1886.

Katoh, K., and Standley, D. M. 2013. MAFFT multiple sequence alignment software version 7: Improvements in performance and usability. Mol. Biol. Evol. 30:772-780.

Liang, X., Bushman, F. D., and FitzGerald, G. A. 2015. Rhythmicity of the intestinal microbiota is regulated by gender and the host circadian clock. Proc. Natl. Acad. Sci. USA 112:10479-10484.

Lindow, S. E., and Brandl, M. T. 2003. Microbiology of the phyllosphere. Appl. Environ. Microbiol. 69:1875-1883.

Lopez-Velasco, G., Carder, P. A., Welbaum, G. E., and Ponder, M. A. 2013. Diversity of the spinach (Spinacia oleracea) spermosphere and phyllosphere bacterial communities. FEMS Microbiol. Lett. 346:146-154.

Lopez-Velasco, G., Tydings, H. A., Boyer, R. R., Falkinham, J. O., and Ponder, M. A. 2012. Characterization of interactions between Escherichia coli O157: $\mathrm{H} 7$ with epiphytic bacteria in vitro and on spinach leaf surfaces. Int. J. Food Microbiol. 153:351-357.

Lynch, M. F., Tauxe, R. V., and Hedberg, C. W. 2009. The growing burden of foodborne outbreaks due to contaminated fresh produce: Risks and opportunities. Epidemiol. Infect. 137:307-315.

Mandal, S., Van Treuren, W., White, R. A., Eggesbo, M., Knight, R., and Peddada, S. D. 2015. Analysis of composition of microbiomes: A novel method for studying microbial composition. Microbiol. Ecol. Health Dis. 26: e27663.

McDonald, D., Clemente, J. C., Kuczynski, J., Rideout, J. R., Stombaugh, J., Wendel, D., Wilke, A., Huse, S., Hufnagle, J., Meyer, F., Knight, R., and Caporaso, J. G. 2012. The biological observation matrix (BIOM) format or: How I learned to stop worrying and love the ome-ome. Gigascience 1:e7.

Norton-Brandao, D., Scherrenberg, S. M., and van Lier, J. B. 2013. Reclamation of used urban waters for irrigation purposes-A review of treatment technologies. J. Environ. Manage. 122:85-98.

Parada, A. E., Needham, D. M., and Fuhrman, J. A. 2016. Every base matters: Assessing small subunit rRNA primers for marine microbiomes with mock communities, time series and global field samples. Environ. Microbiol. 18: 1403-1414.

Parsons, L. R., Sheikh, B., Holden, R., and York, D. W. 2010. Reclaimed water as an alternative water source for crop irrigation. HortScience 45:1626-1629.

Price, M. N., Dehal, P. S., and Arkin, A. P. 2010. FastTree 2-approximately maximum-likelihood trees for large alignments. PLoS One 5:e9490.

Ramamurthy, T., Ghosh, A., Pazhani, G. P., and Shinoda, S. 2014. Current perspectives on viable but non-culturable (VBNC) pathogenic bacteria. Front. Public Health 2:e2014.

Salem, T. A., Omar, M. E. D. M., and El Gammal, H. A. A. 2017. Evaluation of fog and rain water collected at Delta Barrage, Egypt as a new resource for irrigated agriculture. J. Afr. Earth Sci. 135:34-40.

Scott, C. A., Faruqui, N. I., and Raschid-Sally, L. 2004. Wastewater use in irrigated agriculture: Management challenges in developing countries. Pages 1-208 in: Wastewater Use in Irrigated Agriculture: Confronting the Livelihood and Environmental Realities. C. A. Scott, N. I. Faruqui, and L. Raschid-Sally, eds. CABI Publishing, Oxfordshire, U.K.

Semenov, A. M., Kupriyanov, A. A., and van Bruggen, A. H. C. 2010. Transfer of enteric pathogens to successive habitats as part of microbial cycles. Microbiol. Ecol. 60:239-249.

Semenov, A. V., van Overbeek, L., Termorshuizen, A. J., and van Bruggen, A. H. C. 2011. Influence of aerobic and anaerobic conditions on survival of Escherichia coli $\mathrm{O} 157: \mathrm{H} 7$ and Salmonella enterica serovar Typhimurium in Luria-Bertani broth, farm-yard manure and slurry. J. Environ. Manage. 92: 780-787.

Solomon, E. B., Potenski, C. J., and Matthews, K. R. 2002a. Effect of irrigation method on transmission to and persistence of Escherichia coli $\mathrm{O} 157: \mathrm{H} 7$ on lettuce. J. Food Prot. 65:673-676.

Solomon, E. B., Yaron, S., and Matthews, K. R. 2002b. Transmission of Escherichia coli $\mathrm{O} 157: \mathrm{H} 7$ from contaminated manure and irrigation water to lettuce plant tissue and its subsequent internalization. Appl. Environ. Microbiol. 68:397-400.

Suarez, C., Ratering, S., Kramer, I., and Schnell, S. 2014. Cellvibrio diazotrophicus sp. nov., a nitrogen-fixing bacteria isolated from the rhizosphere of salt meadow plants and emended description of the genus Cellvibrio. Int. J. Syst. Evol. Microbiol. 64:481-486.

Telias, A., White, J. R., Pahl, D. M., Ottesen, A. R., and Walsh, C. S. 2011. Bacterial community diversity and variation in spray water sources and the tomato fruit surface. BMC Microbiol. 11:81. 
Tournas, V. H. 2005. Spoilage of vegetable crops by bacteria and fungi and related health hazards. Crit. Rev. Microbiol. 31:33-44.

Uba, B. N., and Aghogho, O. 2000. Rainwater quality from different roof catchments in the Port Harcourt district, Rivers State, Nigeria. J Water Supply Res Technol 49:281-288.

Uyttendaele, M., Jaykus, L. A., Amoah, P., Chiodini, A., Cunliffe, D., Jacxsens, L., Holvoet, K., Korsten, L., Lau, M., McClure, P., Medema, G., Sampers, I., and Jasti, P. R. 2015. Microbial hazards in irrigation water: standards, norms, and testing to manage use of eater in fresh produce primary production. Compr. Rev. Food Sci. Food Saf. 14:336-356.

Vazquez-Baeza, Y., Pirrung, M., Gonzalez, A., and Knight, R. 2013. EMPeror: A tool for visualizing high-throughput microbial community data. Gigascience 2:16.

Vetrovsky, T., and Baldrian, P. 2013. The variability of the 16S rRNA gene in bacterial genomes and its consequences for bacterial community analyses. PLoS One 8:e57923.

Vorholt, J. A. 2012. Microbial life in the phyllosphere. Nat. Rev. Microbiol. 10: 828-840.

Wang, Z., Li, J. S., and Li, Y. F. 2017. Using reclaimed water for agricultural and landscape irrigation in China: A review. Irrig. Drain. 66:672-686.
Weng, S. C., Luo, Y. G., Li, J., Zhou, B., Jacangelo, J. G., and Schwab, K. J. 2016. Assessment and speciation of chlorine demand in fresh-cut produce wash water. Food Control 60:543-551.

Williams, T. R., Moyne, A. L., Harris, L. J., and Marco, M. L. 2013. Season, irrigation, leaf age, and Escherichia coli inoculation influence the bacterial diversity in the lettuce phyllosphere. PLoS One 8:e68642.

Wyenandt, A., Arancibia, R., Hamilton, G., Kuhar, T., van Vuuren, M., and VanGessel, M. 2018. Mid-Atlantic commercial vegetable production recommendations. Penn State Extension. AGRS-028.

Yang, C. H., Crowley, D. E., Borneman, J., and Keen, N. T. 2001. Microbial phyllosphere populations are more complex than previously realized. Proc. Natl. Acad. Sci. USA 98:3889-3894.

Yin, H. B., Gu, G., Nou, X., and Patel, J. 2018b. Impact of wastewater and roofharvest water irrigation on microbial quality of spinach. International Association of Food Protection Annual Meeting P1-162.

Yin, H. B., Nou, X., Gu, G., and Patel, J. 2018a. Microbiological quality of spinach irrigated with reclaimed wastewater and roof-harvest water. J. Appl. Microbiol. 125:133-141.

Yin, H. B., and Patel, J. 2018. Comparison of methods to determine the microbial quality of alternative irrigation waters. Agric. Water Manage. 201:38-45. 